\title{
Revisiting Drug Compliance: The Need for a Holistic Approach in the Treatment of Severe Mental Disorders
}

\author{
К проблеме медикаментозного комплайенса: необходимость целостного \\ подхода в терапии тяжёлых психических расстройств \\ DOI:10.17816/CP93
}

Original article

\author{
Mikhail Yu. Sorokin, ${ }^{1}$ Nikolay G. Neznanov, ${ }^{1,2}$ \\ Natalia B. Lutova, ${ }^{1}$ Viktor D. Wied ${ }^{1}$ \\ ${ }^{1}$ V.M. Bekhterev National Medical Research Center \\ of Psychiatry and Neurology, Saint-Petersburg, Russia; \\ ${ }^{2}$ I.P. Pavlov First Saint-Petersburg State Medical University, \\ Saint-Petersburg, Russia \\ The article can be use under the CC BY-NC-ND 4.0 license \\ (c) Authors, 2021
}

\author{
Михаил Ю. Сорокин, ${ }^{1}$ Николай Г. Незнанов, ${ }^{1,2}$ \\ Наталия Б. Лутова, ${ }^{1}$ Виктор Д. Вид ${ }^{1}$ \\ ${ }^{1}$ НМИЦ ПН им. В.М. Бехтерева, Санкт-Петербург, Россия; \\ 2 ПСПбГму им. И.В. Павлова, Санкт-Петербург, Россия
}

Личензия CC BY-NC-ND 4.0

(c) Коллектив авторов, 2021

\section{ABSTRACT}

INTRODUCTION: The limited practice of depot antipsychotics and psychoeducation use, recommended for overcoming the noncompliance of patients with severe mental disorders, is linked to a high incidence of treatment violation. Therefore, the development of personalized mental healthcare approaches is a crucial healthcare task.

AIM: To describe and differentiate the role of clinical, social and psychological factors that lead to different level of treatment engagement of psychiatric inpatients.

METHODS: Secondary analysis of findings from 91 inpatients, based on the Treatment Motivation Assessment Questionnaire and Medication Compliance Scale, as well as the Scale of Internalized Stigma of Mental IIIness and Perceived Discrimination and Devaluation Scale. Factorial analysis, cluster analysis and analysis of variance with p-level=0.05 and the calculation of the effect size (ES) according to Cohen's $d$ and Cramer's V were used.

RESULTS: The nature of therapy compliance in various categories of patients is mediated differentially, including: the severity of negative symptoms ( $E S=0.29)$, the global level of functioning and work maladjustment $(E S=0.23-0.26)$, various motivational and behavioral styles $(E S \geq 0.74)$ and the intensity of psychiatric stigmatization $(E S \geq 0.88)$.

CONCLUSIONS: Consideration of the clinical, social and psychological factors should empirically determine the strategies for the personalized use of prolonged antipsychotics and socio-psychotherapeutic interventions when developing an individual treatment plan for psychiatric in-patients.

\section{АННОТАЦИЯ}

АКТУАЛЬность: Ограниченная практика применения депо-антипсихотиков и психообразования, рекомендуемых для преодоления нонкомплайенса пациентов с тяжелыми психическими расстройствами, сочетается с сохраняющейся высокой частотой нарушений режима лечения. Это определяет разработку персонализованных подходов психиатрической помощи в качестве актуальной задачи здравоохранения. 
ЦЕЛЬ: Дифференцированное описание роли клинических и социально-психологических факторов, соучаствующих в формировании разной включенности пациентов психиатрического стационара в терапию.

МАТЕРИАЛ И МЕТОДЫ: Вторичный анализ данных 91 пациента психиатрического стационара с верификацией оригинальной кластерной модели включенности в лечебный процесс на основании данных Treatment Motivation Assessment Questionnaire, Medication Compliance Scale, а также Scale of Internalized Stigma of Mental IIIness и Perceived Discrimination and Devaluation Scale. Использованы факторный, кластерный и дисперсионный анализы с p-level=0.05 и расчетом размера эффектов (ES) по Cohen's d и Cramer's V.

РЕзУЛЬТАТЫ: Характер сотрудничества в терапии у разных категорий пациентов опосредован дифференцированно: выраженностью негативной симптоматики (ES=0.29), глобальным уровнем функционирования и трудовой дезадаптацией (ES=0.23-0.26), различными мотивационно-поведенческими стилями $(E S \geq 0,74)$ и интенсивностью психиатрической стигматизации (ES $\geq 0.88)$.

Выводы: Учет комплекса клинических и социально-психологических факторов эмпирически обуславливает стратегии персонализированного применения пролонгированных форм антипсихотиков и социо-психотерапевтических интервенций при разработке индивидуального плана лечения пациентов психиатрического стационара.

Key words: treatment adherence and compliance; patient engagement; motivation; mental disorders; stigma Ключевые слова: приверженность лечению и комплайенс; вовлеченность пациента; мотивация; психические расстройства; стигма

\section{INTRODUCTION}

The traditional approach to achieving high adherence to treatment in patients with severe mental disorders is the widest possible use of depot antipsychotics. However, despite the general consensus on the described strategy, ${ }^{1}$ the practice of using prolonged-release antipsychotics in various healthcare institutions remains inconsistent and, even taking into account the greater cost, is unreasonably limited. ${ }^{2}$

Among the barrier factors for the widespread use of depot drugs in clinical work are organizational factors (a limited number of drugs paid for from insurance funds due to a high cost for depot antipsychotics), the doctors ' attitude (difficulties in dose control, subjective perception of the appointment as coercion of the patient, established clinical practice), or factors related to the patient, such as a fear of painful injections, lack of information or perception of depot therapy as a coercive measure. ${ }^{3} \mathrm{At}$ the same time, an analysis of the frequency of prolongedrelease antipsychotics use indicates their predominant prescription in situations of clinical uncertainty: among $37.8 \%$ of patients with polypharmacy, ${ }^{4}$ as well as among those with increased aggressiveness ${ }^{5}$ and those who rarely seek in-patient care. ${ }^{6}$ At the same time, the question remains unclear whether such categories of patients benefit the most from the depot therapy. On the contrary, some clinical recommendations indicate the validity of using depot drugs not only for the treatment of severe patients, but also as a choice for routine antirelapse therapy. ${ }^{7}$

It is noteworthy that psychiatrists themselves are often biased towards prolonged-release antipsychotics, and in a hypothetical situation of their own treatment they would prefer taking oral drugs. ${ }^{8}$ This prejudice associated with changing patterns of behavior is believed to be one of the key markers of the stigmatization process. ${ }^{9}$ Stereotyping attitudes towards patients and strategies for choosing drug therapy can determine cognitive biases. Then, in order to increase adherence to treatment, depot therapy is prescribed algorithmically and without considering recommendations on the need to combine prolonged-release antipsychotics with psychoeducation programs to achieve the desired level of compliance. ${ }^{10}$

There is solid evidence that different categories of patients demonstrate significantly different rates 
of treatment adherence, even with depot antipsychotics, depending on their motivation for treatment and attitude to the disease. ${ }^{11}$ At the same time, in addition to the patient's own motivation for treatment, the perceived external pressure from the patient's environment is an independent factor in increasing involvement in the therapeutic process, acting along with the factors of distress and insight on the disease. ${ }^{12}$

From this review of the literature, it follows that the task of forming a high adherence to antipsychotic therapy in severe mental disorders is intractable in the case of a mechanistic prescription of depot drugs to the most severe patients. On the contrary, the benefits of therapy with prolonged-release antipsychotics could be available to a larger number of patients through the development of personalized rehabilitation programs that include, along with the individualized selection of medical therapy, taking into account the socio-psychological conditions of a mental disorder development and the patient's own motives for therapy.

The purpose of the study is a differentiated description of the role of clinical and socio-psychological factors involved in the formation of different levels of in-patient engagement in the treatment process. The hypothesis of the study was based on the assumption that the level of involvement of patients with mental disorders in therapy is available for instrumental analysis and can be increased through rehabilitation strategies addressed to morbid (biological), motivational (psychological), and socio-behavioral factors specific to different types of patients. The implementation of the study was carried out through a sequential completion of tasks:

1) verification, based on the objectively observed behavior of patients during treatment and their therapeutic alliance, of the original cluster model of involvement in the treatment process, based on an instrumental assessment of therapeutic motivation and the structure of compliance

2) description of targeted strategies to increase adherence to treatment, depending on the main clinical, psychological and behavioral parameters: severity of symptoms, characteristics of the course of the disorder and attitude to the disease, and the therapeutic alliance, in each of the selected types of patients.

\section{METHODS}

A sample of 91 patients of the V.M. Bekhterev National Research Medical Center for Psychiatry and Neurology was studied, clinical and experimental psychological data were subjected to secondary analysis in February 2020, after identifying the typology of patients based on their motivation for treatment and profile of drug compliance. A detailed description of the examined respondents is presented in Table 1. The study protocol was implemented in accordance with the principles of the Declaration of Helsinki, GCP and approved at a meeting of the Independent Ethics Committee at the V.M. Bekhterev National Research Medical Center for Psychiatry and Neurology No. EK-I-105/18 (25.09.2018).

To identify the reasons for the motivation of patients included in the study, as well as to operationalize their drug compliance, the original psychometric instruments were used. The Treatment Motivation Assessment Questionnaire (TMAQ) was applied, based on the Treatment Motivation Scale developed in the Department of Integrative Pharmaco-Psychotherapy. ${ }^{13}$ Therapeutic motivation is described quantitatively - through the total indicator of its intensity, and also qualitatively when comparing the parameters of individual sections with those standardized for six levels or four factors of the questionnaire. It has demonstrated good internal consistency (Cronbach's alpha 0.842), and its external as well as meaningful validity has been established previously. ${ }^{13,14}$

To assess the multifactorial nature of patient compliance, the Medication Compliance Scale (MCS) ${ }^{15}$ was used, which is answered by a doctor based on complete clinical information and medical history of the patient. Individual MCS items include the study of the patient's clinical condition according to the Brief Psychiatric Rating Scale (BPRS), ${ }^{16}$ the Negative Symptom Rating Scale (SANS), ${ }^{17}$ and the Global Assessment of Functioning (GAF). ${ }^{18}$ In addition to the original psychometric instruments, the Internalized Stigma of Mental Illness (ISMI) scale ${ }^{19}$ and the Perceived Discrimination and Devaluation Scale (PDD) ${ }^{20}$ were used.

The data obtained were statistically analysed using the SPSS 16.0 software package. The principal component method with varimax rotation was used to factorize the data. The k-means cluster analysis was used. Analysis of variance was performed using ANOVA and the Student's t-test for parametric data, Kruskal-Wallis $\mathrm{H}$-criterion 
and Mann-Whitney U-criterion for nonparametric data and Pearson Chi-square for rated values. The data distribution was assessed using the Kolmogorov-Smirnov z-criterion. For descriptive statistics of revealed significant differences, we used the calculation of the size of effects according to the Cohen's d and Cramer's V criteria.

\section{Study procedures}

Enrolment in the study was carried out after obtaining voluntary informed consent. The inclusion criteria were: 1) being in in-patient treatment in the department of integrative pharmaco-psychotherapy of patients with mental disorders, 2) readiness and ability to undergo psychometric examination in accordance with the protocol, and 3) fluency in Russian. Noninclusion criteria: the severity of the positive symptoms or cognitive impairments, which determines the patient's inability to correctly answer the questions of the original psychometric instruments. The exclusion criterion was the withdrawal of consent to participate at any stage of the study.

The most typical options for the involvement of inpatients in the treatment process were established in the cluster analysis of psychometric data: standardized indicators of the compliance scale subscales and four factors of the motivation assessment questionnaire. ${ }^{21}$ The selected groups of patients had the most similar structures of motivation for treatment and drug compliance within the cluster, but they differed maximally when compared with each other (Figure 1).

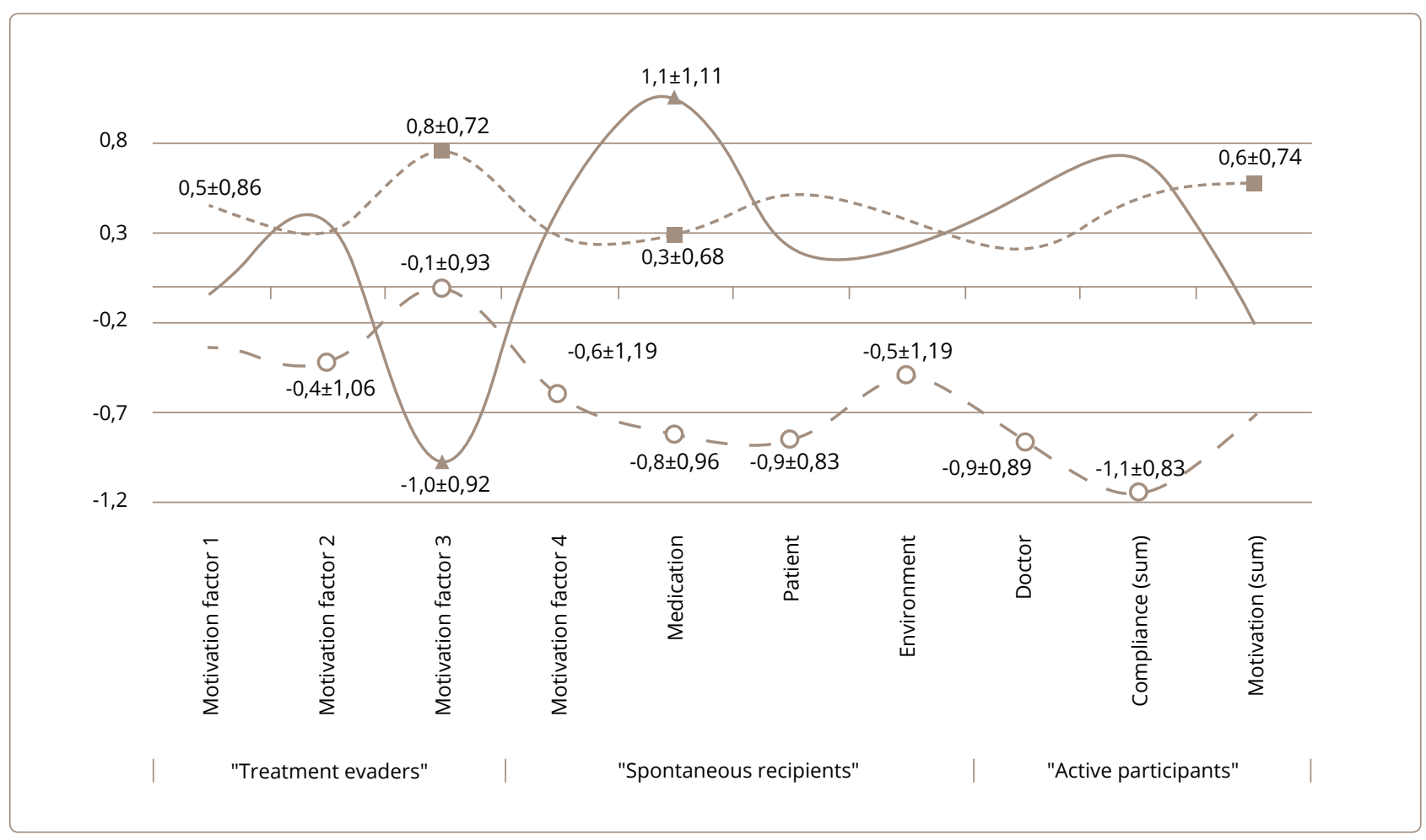

Figure 1. Typology of patients depending on the prevailing structure of treatment motivation and the corresponding profile of medication compliance (means and standard deviations of questionnaires standardized indices)

Footnote. Parameters of the Treatment motivation assessment questionnaire (TMAQ): factor 1 - the psychoeducative component of the internal disease picture, factor 2 - the insight into the necessity of the treatment, factor 3 - the insight into the psychological mechanism of the morbid social maladjustment, factor 4 - the willingness to an active participation in the treatment process, motivation - the sum total of TMAQ. Subscales of Medication Compliance Scale (MCS): medication - the attitude to medication, patient - factors referring to the patient, environment - factors referring to the environment of the patient, doctor - factors referring to the therapist, compliance - the sum total of the MCS. Marked standardized indices with significant intergroup differences, Cohen's $d \geq 0.74 ; p \leq 0.05$. 


\section{RESULTS}

Patient clusters, differing in the degree of involvement in therapy, were numerically comparable (Table 1 ) and did not differ in the main socio-demographic and clinical characteristics (gender, age, education, marital status and children, nosology, duration of the disease, frequency of hospitalizations, severity of productive symptoms), as well as the frequency of taking antipsychotics of the $1^{\text {st }}$ or the $2^{\text {nd }}$ generations, antidepressants and mood stabilizers.

The fundamental difference was in the behavior of patients assigned to different clusters during drug treatment and in their therapeutic alliance (Table 2).

The proportion of patients in cluster 1 was overwhelming among respondents with a low therapeutic alliance (MCS 4.1). Often, they were unable to maintain drug compliance on their own. The adherence disorder for these "evading" patients was stable throughout the whole available medical history (MCS 1.5). Patients in this cluster included those with more frequent use of nonrecommended drugs and / or irregular use of recommended medications. The search for factors involved in the formation of low adherence to treatment in cluster 1 revealed the most pronounced morbid changes in this group of patients. They suffered from negative symptoms, and, compared to patients in cluster 3 , were more socially maladjusted (Table 1).

Cluster 2 included half of the subgroup of respondents with a high therapeutic alliance, as well as $19 \%$ of patients who needed external control of medication and 30\% who were self-medicating at the time of the current hospitalization. Nevertheless, this cluster included the

Table 1. Sociological and clinical features of patients after clusterization

\begin{tabular}{|c|c|c|c|c|c|}
\hline & & Cluster $1 \mathrm{~N}=\mathbf{2 9}$ & Cluster $\mathbf{2} \mathbf{N}=\mathbf{2 3}$ & Cluster $3 \mathrm{~N}=39$ & p-level of differences \\
\hline \multirow{2}{*}{ Sex } & Male & 15 & 8 & 11 & \multirow{2}{*}{$\geq 0.05$} \\
\hline & Female & 14 & 15 & 28 & \\
\hline \multicolumn{2}{|c|}{ Mean age, years, M [S.D.] } & $30.7[9.8]$ & $36.1[12.5]$ & $35.1[13.2]$ & $\geq 0.05$ \\
\hline \multirow{3}{*}{ Occupation } & employed & 5 & 9 & 20 & \multirow{3}{*}{$p=0.046$} \\
\hline & unemployed & 23 & 12 & 17 & \\
\hline & disability pension & 1 & 2 & 2 & \\
\hline \multirow{2}{*}{ Marital status } & married & 9 & 11 & 10 & \multirow{2}{*}{$\geq 0.05$} \\
\hline & single & 20 & 12 & 29 & \\
\hline \multirow{3}{*}{ Education } & primary & 11 & 4 & 8 & \multirow{3}{*}{$\geq 0.05$} \\
\hline & secondary & 8 & 7 & 5 & \\
\hline & higher & 10 & 12 & 26 & \\
\hline \multirow{4}{*}{ Diagnosis (ICD-10) } & $\mathrm{F} 2$ & 24 & 15 & 30 & \multirow{4}{*}{$\geq 0.05$} \\
\hline & F3 & 2 & 4 & 2 & \\
\hline & $\mathrm{F} 4+\mathrm{F} 6$ & 1 & 3 & 5 & \\
\hline & FO & 2 & 1 & 2 & \\
\hline \multicolumn{2}{|c|}{ IIIness duration, years, M [S.D.] } & $8.9[9.5]$ & $10.4[11.0]$ & $8.1[8.0]$ & $\geq 0.05$ \\
\hline \multicolumn{2}{|c|}{ Inter hospitalization rate, months, M [S.D.] } & $24.0[13,4]$ & $34.3[27.5]$ & $25.7[21.6]$ & $\geq 0.05$ \\
\hline \multirow{3}{*}{$\begin{array}{l}\text { BPRS } \\
\text { (positive symptoms) }\end{array}$} & $\geq 60$ points & 12 & 6 & 7 & \multirow{3}{*}{$\geq 0.05$} \\
\hline & 40-60 points & 14 & 12 & 24 & \\
\hline & $\leq 40$ points & 3 & 5 & 8 & \\
\hline \multirow{3}{*}{$\begin{array}{l}\text { SANS } \\
\text { (negative symptoms) }\end{array}$} & $\geq 60$ points & 13 & 5 & 5 & \multirow{3}{*}{$p=0.004$} \\
\hline & $30-60$ points & 13 & 8 & 14 & \\
\hline & $\leq 30$ points & 3 & 10 & 20 & \\
\hline \multirow{3}{*}{$\begin{array}{l}\text { GAF } \\
\text { (global functioning) }\end{array}$} & $\leq 40$ points & 13 & 6 & 4 & \multirow{3}{*}{$p=0.015$} \\
\hline & $40-60$ points & 13 & 11 & 28 & \\
\hline & $\geq 60$ points & 3 & 6 & 7 & \\
\hline
\end{tabular}


rarest history of drug compliance violations (Table 2). Interestingly, such "recipients of therapy" were more inclined to discriminate against other mentally ill patients than in cluster 3 (Figure 2).

In cluster 3, with the maximum indicators of the intensity of therapeutic motivation, the most common was the average level of therapeutic alliance and attitude to medication. Unexpectedly, this group included half of the patients who have arbitrarily discontinued drug therapy in the past. It is important to note separately that the respondents here were inclined to actively resist psychiatric stigmatization (Figure 2).

Table 2. Differences in the prevalence of compliance violation history between groups of patients after clustering

\begin{tabular}{|c|c|c|c|c|}
\hline \multirow{2}{*}{$\begin{array}{l}\text { Predominant behavioral pattern in medication } \\
\text { compliance scale }\end{array}$} & \multicolumn{3}{|c|}{ Behavior occurrence } & \multirow{2}{*}{ Criterion of differences } \\
\hline & Cluster 1 & Cluster 2 & Cluster 3 & \\
\hline \multicolumn{5}{|l|}{ 1.1 Behavior during medication } \\
\hline Evasion of medication intake & 3 & 0 & 0 & \multirow{3}{*}{$\begin{array}{l}p=0,0001 ; \\
\chi^{2}=23.4, d f=4, \\
\text { Cramer's } V=0.51\end{array}$} \\
\hline Externaly controlled drugs intake & 18 & 6 & 8 & \\
\hline Self-controlled drugs intake & 8 & 17 & 31 & \\
\hline \multicolumn{5}{|l|}{ 1.5 Noncompliance history } \\
\hline Nonrecommended drugs intake & 5 & 1 & 2 & \multirow{5}{*}{$\begin{array}{l}\mathrm{p}=0,002 ; \\
\chi^{2}=24.1, \mathrm{df}=8, \\
\text { Cramer's } \mathrm{V}=0.52\end{array}$} \\
\hline Self-discontinuation of medication & 14 & 5 & 19 & \\
\hline Irregular intake of medication & 4 & 0 & 2 & \\
\hline Self-reduced dosage & 0 & 4 & 4 & \\
\hline Absence of noncompliance & 3 & 13 & 12 & \\
\hline \multicolumn{5}{|l|}{ 4.1 Therapeutic alliance } \\
\hline Low & 15 & 0 & 1 & \multirow{3}{*}{$\begin{array}{l}\mathrm{p}=0,0001 ; \\
\chi^{2}=41.1, \mathrm{df}=4, \\
\text { Cramer's } \mathrm{V}=0.67\end{array}$} \\
\hline Medium & 13 & 12 & 28 & \\
\hline High & 1 & 11 & 10 & \\
\hline
\end{tabular}

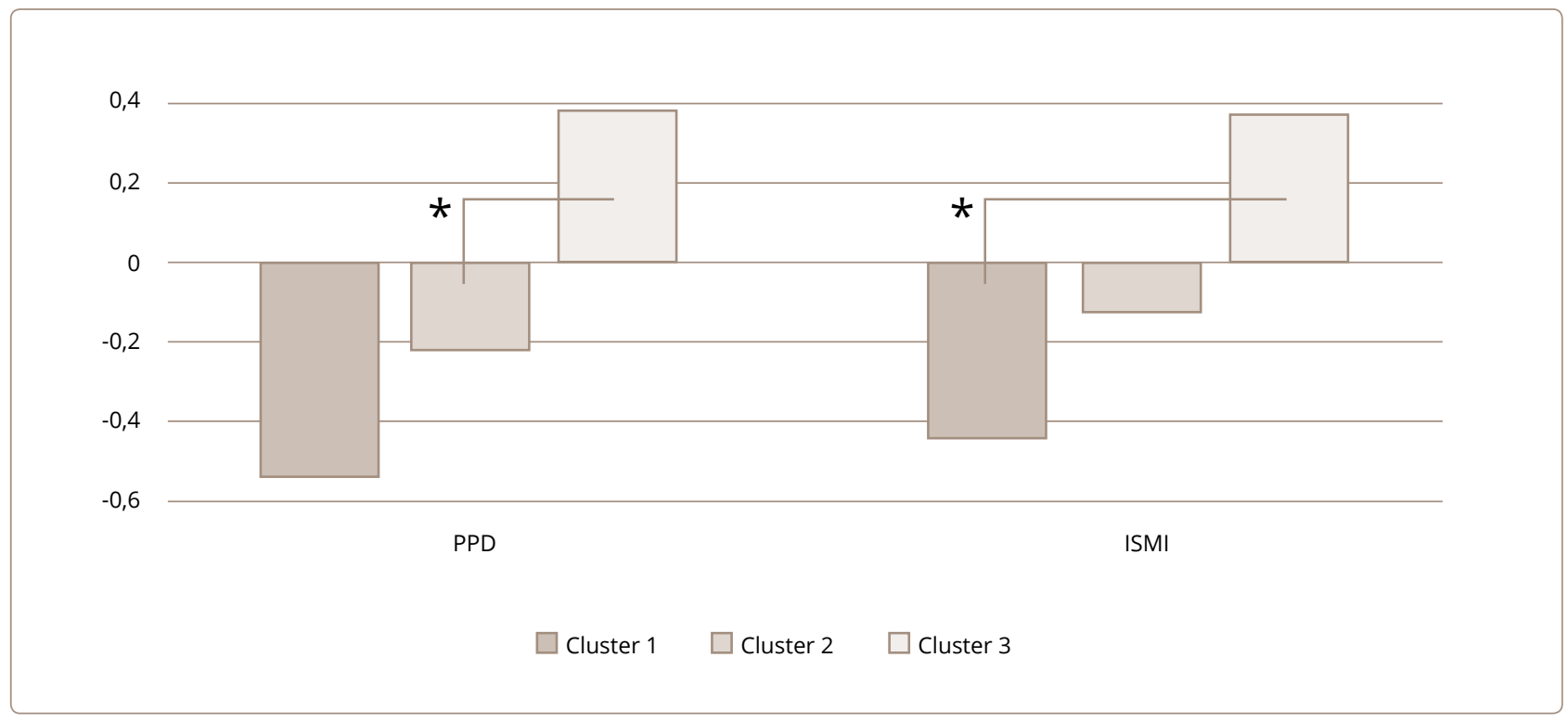

Figure 2. Standardized scores for psychiatric stigmatization in patients from different clusters (means and standard deviations) Footnote. PDD - Perceived Discrimination and Devaluation Scale (low scores reflect higher external stigmatization); ISMI discrimination resistance subscale of Internalized Stigma of Mental IIIness; Cluster 1 - patients «avoiding treatment»; Cluster 2 «passive recipients» of treatment; Cluster 3 «active treatment participants». * $p<0,05$ 


\section{DISCUSSION}

The study confirmed the hypothesis of the complex nature of the phenomenon of long-term adherence to drug therapy in psychiatric in-patients. The fact of a high intensity of motivation for treatment, without its nature assessment, does not allow for predicting a favourable attitude towards medication and a high therapeutic alliance in patients with severe mental disorders. The data obtained demonstrate that, in addition to the factor of insight into the disease described earlier in the literature, ${ }^{11}$ the processes of psychiatric stigmatization play a significant role in the formation of adherence to therapy in hospital patients with severe mental disorders.

Long-term adherence to antipsychotic therapy is critical for the decrease of productive symptoms and the prevention of maladjustment in schizophrenia patients. ${ }^{22}$ Based on the data of the analysed sample, it was revealed that among patients with impaired functioning, unfavourable social and labour status and the most pronounced negative symptoms, low drug compliance is associated with impaired motivation for treatment. Thus, the patients most in need of stable drug treatment did not have sufficient psychological resources to maintain a therapeutic alliance and adherence to treatment. The prevalence of the irregular use of drugs in such "difficult" patients determines the rationale that $32 \%$ of the examined patients should be treated with prolongedrelease antipsychotics in combination with the active formation and maintenance of a therapeutic alliance, their family should be involved in psychoeducation and training in the supervision of the patient's medication.

Only one fourth of the sample showed long-term adherence to therapy. Adherence was supported by a moderate intensity of motivation for treatment, which became an illustration of the applicability of the "law of optimum" in relation to therapeutic motivation in patients with severe mental disorders. ${ }^{23}$ However, patient compliance is not the only barrier to the use of long-acting antipsychotics. Since they discriminated against other psychiatric patients and showed a relative decrease in the motivation for treatment, it is legitimate to judge the limited self-identification of "recipients of therapy" as patients in need of psychiatric care. Thus, it is more important for this category of patients to prevent the formation of a semantic connection between the depot as a therapeutic option and the risk of limiting their freedom in choosing a treatment strategy, rather than ensuring the constant receipt of the antipsychotic in the form of a depot.

A significant (43\%) part of the sample (highly functioning patients with no signs of severe abulia) were active in opposing discrimination. This is consistent with literature data on the multidimensional relationship between motivational processes, internal stigma, and disease outcome. ${ }^{24}$ Active and purposeful actions of patients within the therapeutic program are not only a reflection of their overall high level of functioning, but also an indirect effect of overcoming self-stigmatization affected by their involvement in the rehabilitation system. Probably, among the "active participants" of therapy, the motive of resistance to stigmatization had an expansive subjective interpretation in the form of distancing from the doctor (middle-level therapeutic alliance) and, thus, was associated with a medical history aggravated by therapy discontinuation. These findings highlight the potential for the increased use of longacting antipsychotics also in patients who demonstrate an active stance during treatment, when combined with rehabilitation interventions aimed at correcting dysfunctional beliefs about illness and medication.

A potential limitation of the study is the nosological heterogeneity of the sample. However, a significant part of the social and psychological factors that determine involvement in the therapeutic process is the same in various mental disorders. Therefore, samples mixed by diagnosis are widely represented in studies addressed to the psychology of the treatment process. ${ }^{25,26}$ Our sample of patients reflects the naturalistic nosological profile of patients with mental disorders seeking for in-patient care. In addition, there were no statistically significant nosological differences between the identified clusters of patients with different levels of inclusion in therapy. Thus, the objective of the study did not depend on bias in the selection of patients.

\section{CONCLUSION}

Verification of the original cluster model has demonstrated the applicability of instrumental assessments of motivation to treatment and drug compliance to determine the types of treatment involvement of patients with mental disorders. Analysis of the differences between the identified clusters of "active participants", "passive recipients" and patients 
that "avoided therapy" helps to objectively assess the multifactorial nature of patients' behavior during the treatment process. The level of compliance of patients with severe mental disorders is mediated by the severity of negative symptoms and social maladjustment, various motivational and behavioral styles, and the intensity of psychiatric stigmatization. Taking these factors into account empirically determines the strategies for the personalized use of prolonged forms of antipsychotics when developing an individual treatment plan for psychiatric in-patients.

\section{Manuscript process:}

Submitted: 18.07.2021

Accepted: 23.08.2021

Published: 30.09 .2021

Funding: The study was performed without external funding. The study was performed in accordance with the World Medical Association Declaration of Helsinki (2013). All participants gave their consent to the processing of personal data before enrolment. Approval was obtained from the local IRB at V.M. Bekhterev National Medical Research Center for Psychiatry and Neurology.

Conflict of interests: The authors report no conflicts of interest.

Authors" contribution: N.G. Neznanov, M.Yu. Sorokin concept and design of the article; M.Yu. Sorokin literature searches; M.Yu. Sorokin - writing the manuscript; N.B. Lutova, V.D. Wied - comments on the draft paper; N.G. Neznanov, N.B. Lutova - revisioning the manuscript; N.G. Neznanov, N.B. Lutova, V.D. Wied approval of the final version.

\section{Correspondence to:}

\section{Mikhail Yu. Sorokin}

m.sorokin@list.ru

\section{For citation:}

Sorokin MYu, Neznanov NG, Lutova NB, Wied VD. Revisiting Drug Compliance: The Need for a Holistic Approach in the Treatment of Severe Mental Disorders. Consortium Psychiatricum. 2021;2(3):17-25. DOI:10.17816/CP93

\section{References}

1. Mosolov S, Tsukarzi E, Alfimov P. Algorithms for biological treatment of schizoprenia. Article in Russian. 2014;(1):27-36.

2. Dyakov I N, Zyryanov SK. Comparative evaluation of clinical and economic efficiency of paliperidone in various dosage forms used in patients with schizophrenia. Article in Russian. Zh Nevrol Psikhiatr Im S S Korsakova. 2017;117(2):85-92. doi:10.17116/ jnevro20171172185-92

3. Lindenmayer JP, Glick ID, Talreja H, Underriner M. Persistent Barriers to the Use of Long-Acting Injectable Antipsychotics for the Treatment of Schizophrenia. J Clin Psychopharmacol. 2020;40(4):346-349. doi:10.1097/JCP.0000000000001225

4. Civan Kahve A, Kaya H, Gul Cakil A, et al. Multiple antipsychotics use in patients with schizophrenia: Why do we use it, what are the results from patient follow-ups? Asian J Psychiatr. 2020;52:102063. doi:10.1016/j.ajp.2020.102063

5. Barbui C, Bertolini F, Bartoli F, et al. Reasons for initiating long-acting antipsychotics in psychiatric practice: findings from the STAR Network Depot Study. Ther Adv Psychopharmacol. 2020;10:2045125320978102. doi:10.1177/2045125320978102

6. Botha UA, Koen L, Joska JA, et al. The revolving door phenomenon in psychiatry: comparing low-frequency and high-frequency users of psychiatric inpatient services in a developing country. Soc Psychiatry Psychiatr Epidemiol. 2010;45(4):461-468. doi:10.1007/s00127-009-0085-6

7. Hasan A, Falkai P, Wobrock T, et al. World Federation of Societies of Biological Psychiatry (WFSBP) guidelines for biological treatment of schizophrenia, part 2: update 2012 on the long-term treatment of schizophrenia and management of antipsychotic-induced side effects. World J Biol Psychiatry. 2013;14(1):2-44. doi:10.3109/15622975. 2012.739708

8. Mendel R, Hamann J, Traut-Mattausch E, et al. 'What would you do if you were me, doctor?': randomised trial of psychiatrists' personal v. professional perspectives on treatment recommendations. $\mathrm{Br}$ J Psychiatry. 2010;197(6):441-447. doi:10.1192/bjp.bp.110.078006

9. Link BG, Phelan JC. Conceptualizing Stigma. Annual Review of Sociology. 2001;27(1):363-385. doi:10.1146/annurev.soc.27.1.363

10. El Abdellati K, De Picker L, Morrens M. Antipsychotic Treatment Failure: A Systematic Review on Risk Factors and Interventions for Treatment Adherence in Psychosis. Front Neurosci. 2020;14:531763. doi:10.3389/fnins.2020.531763

11. Noordraven EL, Wierdsma Al, Blanken P, Bloemendaal AF, Mulder CL. Depot-medication compliance for patients with psychotic disorders: the importance of illness insight and treatment motivation. Neuropsychiatr Dis Treat. 2016;12:269-274. doi:10.2147/NDT.S97883

12. Jochems EC, Duivenvoorden HJ, van Dam A, Mulder CL, van der Feltz-Cornelis CM. Testing the Integral Model of treatment motivation in outpatients with severe mental illness. Motiv Emot. 2018;42(6):816830. doi:10.1007/s11031-018-9708-0

13. Sorokin MY, Lutova NB, Wied VD. The Role of Treatment Motivation Subsystems in the Overall Structure of Compliance in Patients Undergoing Psychopharmacotherapy. Neuroscience and Behavioral Physiology. 2017;47(8):890-894. doi:10.1007/s11055-017-0486-z

14. Lutova NB, Sorokin MY, Makarevich OV, Wied VD. The subjective concept of morbidity: its assessment and connection with the motivation for treatment in persons who underwent psychosis. VM Bekhterev Review of Psychiatry and Medical Psychology. 2020(2):7379. doi:10.31363/2313-7053-2020-2-73-79

15. Lutova NB, Wied VD. The insight and compliance in patients with schizophrenia. Dynamische Psychiatrie. 2016;49(3-6):235-247 
16. Overall J, Gorham D. The Brief Psychiatric Rating Scale. Psychol Rep. 1962;10(3):799-812. doi:10.2466/pr0.1962.10.3.799

17. Andreasen N. Negative Symptoms in Schizophrenia. Arch Gen Psychiatry. 1982;39(7):784. doi:10.1001/archpsyc.1982.04290070020005

18. Salvi G, Leese M, Slade M. Routine use of mental health outcome assessments: choosing the measure. British Journal of Psychiatry. 2005;186(2):146-152. doi:10.1192/bjp.186.2.146

19. Boyd Ritsher J, Otilingam P, Grajales M. Internalized stigma of mental illness: psychometric properties of a new measure. Psychiatry Res. 2003;121(1):31-49. doi:10.1016/j.psychres.2003.08.008

20. Link B, Cullen F, Struening E, Shrout P, Dohrenwend B. A Modified Labeling Theory Approach to Mental Disorders: An Empirical Assessment. Am Sociol Rev. 1989;54(3):400. doi:10.2307/2095613

21. Lutova NB, Sorokin MYu, Wied VD. Structure of motivation for treatment and compliance in psychiatric patients. In: Neznanov NG, Vasileva AV, eds. Dynamic Psychiatry of Gunter Ammon. Identity through the Group. Alta Astra;2018:245-254.

22. Mathews M, Gopal S, Singh A, et al. Comparison of Relapse Prevention with 3 Different Paliperidone Formulations in Patients with Schizophrenia Continuing versus Discontinuing Active Antipsychotic Treatment: A Post-Hoc Analysis of 3 Similarly Designed Randomized Studies. Neuropsychiatr Dis Treat. 2020;16:1533-1542. doi:10.2147/NDT.S221242

23. Teigen KH. Yerkes-Dodson: A Law for all Seasons. Theory \& Psychology. 2016;4(4):525-547. doi:10.1177/0959354394044004

24. Galderisi S, Rossi A, Rocca P, et al. The influence of illness-related variables, personal resources and context-related factors on real-life functioning of people with schizophrenia. World Psychiatry. 2014;13(3):275-287. doi:10.1002/wps.20167

25. Jochems EC, van der Feltz-Cornelis CM, van Dam A, Duivenvoorden $\mathrm{HJ}$, Mulder CL. The effects of motivation feedback in patients with severe mental illness: a cluster randomized controlled trial. Neuropsychiatr Dis Treat. 2015;11:3049-3064. doi:10.2147/NDT.S95190

26. Kortrijk HE, Kamperman AM, Mulder CL. Changes in individual needs for care and quality of life in Assertive Community Treatment patients: an observational study. BMC Psychiatry. 2014;14:306. doi:10.1186/s12888-014-0306-8 